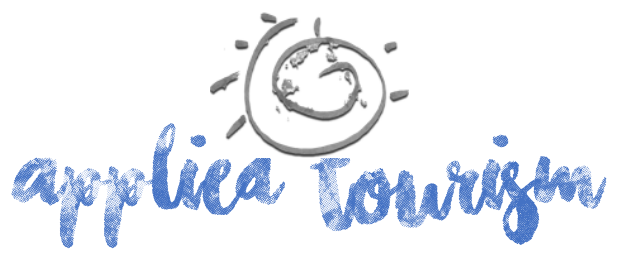

Volume 2, número 3, 2017, p. 115-135

\title{
LAVANDERIA CLASSE A: Um Estudo sobre o Indicador de Desempenho Relave no Processamento de Lavagem do Enxoval Hospitalar
}

\author{
Caroline Garaluz Acosta \\ Bacharel em Hotelaria \\ Universidade do Oeste do Paraná - UNIOESTE \\ carolgaraluz@hotmail.com \\ Nandri Candida Strassburger \\ Mestre em Turismo \\ Universidade do Oeste do Paraná- UNIOESTE \\ nandricandida@gmail.com
}

Recebido: 28 de junho, 2017

Aprovado: 27 de outubro, 2017

\section{RESUM0}

Indicadores de desempenho são formas de dimensionar as características de produtos e processos nas organizações. 0 objetivo dessa pesquisa é analisar o indicador de desempenho relave da Lavanderia Classe A, localizada no município de Foz do Iguaçu, Paraná, nos anos de 2013, 2014 e 2015, referente ao processamento de lavagem de enxoval hospitalar. Quanto ao método de pesquisa aplicado, face ao problema e aos objetivos, utilizou-se estudo de caso, de corte qualitativo. No estudo, empregaram-se pesquisa bibliográfica e aplicação de questionário junto à sócia proprietária. 0 resultado sugere que 0 indicador relave atingiu nos dois primeiros anos de funcionamento 4,48\% e 5,01\%, respectivamente, o que levou a gestão substituir os produtos utilizados na lavagem do enxoval. No ano de 2015, após a utilização de um produto a base de enzimas, mesmo tendo ocorrido aumento na quantidade de enxoval processado, 0 indicador apresentou retrocesso, encerrando 0 ano em $4,66 \%$.

Palavras-chaves: Lavanderia; Indicador de desempenho; Relave. 


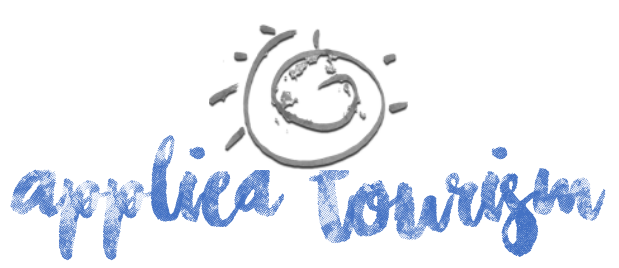

Volume 2, número 3, 2017, p. 115-135

clientes serviço de lavagem de enxovais relacionados tanto ao mercado hoteleiro quanto ao segmento hospitalar. 0 foco desta pesquisa foi 0 segundo segmento.

A Lavanderia Classe A utiliza indicadores para medir o desempenho de suas atividades na empresa, pois através deles a gestão pode avaliar acompanhar se determinada ação atinge ou não seu objetivo. A lavanderia trabalha com indicadores desde 0 início de suas atividades. Além disso, todo processamento de lavagem do enxoval é prestado de acordo com as normas vigentes de órgãos reguladores, como a Anvisa.

A presente pesquisa se justificativa para que se possa viabilizar a análise de um indicador que apresente resultados do processo de lavagem dos enxovais da lavanderia, em específico, o indicador de desempenho relave. Para isso, pretende responder ao seguinte questionamento: de que forma a Lavanderia Classe A utiliza os resultados do indicador de desempenho relave?

Inicialmente, a pesquisa faz um estudo sobre o processo de lavagem do enxoval hospitalar, e, em segundo momento, verifica como a lavanderia utiliza os dados do indicador de desempenho relave. São analisados os dados fornecidos pela empresa referente os anos de 2013, 2014 e 2015. Para tanto, o estudo se propôs a analisar as seguintes variáveis: a) quantidade de roupas processadas durante a lavagem; e b) quantidade de relave durante este período.

\section{Indicadores de Desempenho}

Para Leão, Silva, Alvarenga e Mendonça (2008), indicador é a unidade de análise, quantitativa ou qualitativa, utilizado para representar ou medir um problema, que necessita ser observado em uma situação real. Ainda de acordo com os autores, os indicadores devem atender cinco questões básicas: por que registrar a informação, 


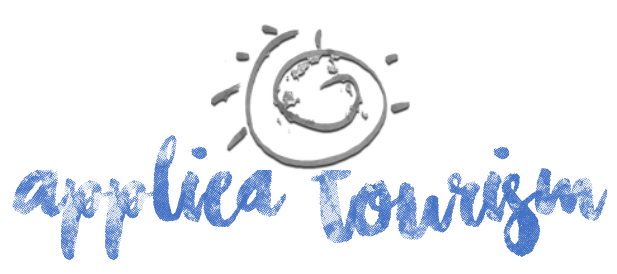

Volume 2, número 3, 2017, p. 115-135

para que será utilizada, quem a utilizará, como será empregada e por quanto tempo será útil.

Para Takashina e Flores (1996), os indicadores são mecanismos de análise para a avaliação de desempenho, que são elaborados e utilizados pelos gerentes com 0 objetivo de atingir as metas, buscando desenvolver e potencializar os processos. Nesse sentido, os autores ressaltam que os indicadores se destinam a elencar áreas com desempenho satisfatório e áreas que melhorias podem ser feitas. Para eles, "os indicadores fornecem subsídios que irão dimensionar tais mudanças, possibilitando maximizar a eficiência e melhoria dos resultados globais" (TAKASHINA \& FLORES, 1996, p. 41).

Para Castelli (2006), os indicadores estão diretamente ligados ao conceito de qualidade, portanto, "satisfazer os clientes significa atender as necessidades de todas as pessoas com as quais a empresa tem compromisso, tais como: colaboradores, clientes, acionistas e vizinhos (comunidade)” (CASTELLI, 2006, p. 74). Ainda de acordo com 0 autor, é preciso manter um canal de diálogo permanente com eles, para evitar desequilíbrio e bloqueio da competitividade e sobrevivência da empresa.

Ao tratar sobre a finalidade de indicadores de desempenho, Kardec et al. (2002) escrevem que a principal finalidade dos indicadores de desempenho é mostrar os pontos fracos, e observá-los, para detectar possíveis problemas que estão causando os resultados indesejados.

Conforme Bittar (2011), para se avaliar e monitorar a qualidade das atividades e serviços, os gestores devem utilizar indicadores de desempenho. Para 0 autor, estes indicadores buscam 0 crescimento da receita, diminuição de custos, consecução da estratégia de investimentos, além de aumentar a produtividade.

Ao tratar sobre a elaboração de indicadores, ele ressalta que, para a criação de indicadores, os gestores devem seguir alguns passos, como: a) saber o que se vai controlar ou medir; b) buscar saber de onde serão extraídas as informações; c) quais serão os métodos que utilizados para analisar os dados obtidos; d) qual a 


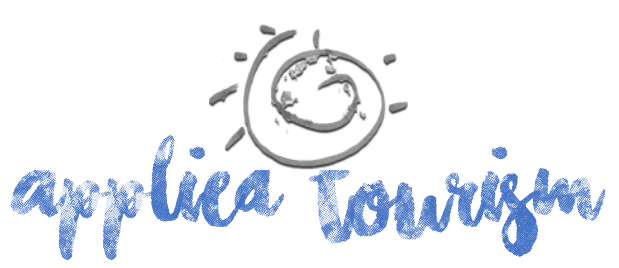

Volume 2, número 3, 2017, p. 115-135

frequência com que estes dados serão extraídos; e e) análise dos seus resultados para chegar a uma tomada de decisões.

Ao discorrer sobre a geração de indicadores, Takashina e Flores (1996) afirmam que os indicadores são elementos primordiais no controle e planejamento das organizações, e são gerados para possibilitar o estabelecimento de metas quantificadas, em que são feitas análise do desempenho para chegar a um determinado objetivo. Para eles, os indicadores estão, em geral, fortemente relacionados aos objetivos e estratégias da organização, pois proporcionam 0 desdobramento das metas dos negócios, permitindo que as melhorias obtidas em cada unidade contribuam para os propósitos globais. Os autores ressaltam que os indicadores "devem ser gerados a partir das necessidades e expectativas dos clientes" (TAKASHINA \& FLORES, 1996, p. 3). Nesse sentido, os autores consideram ser um fator importante considerar os resultados dos indicadores ao se pensar nas estratégias e propósitos da organização.

Na concepção de Takashina e Flores (1996), os indicadores devem ser demonstrados de uma forma que possibilitem e disponibilizem dados e resultados confiáveis, devem garantir sua análise e seu uso, além de mostrar níveis e tendências. De acordo com os autores, os indicadores podem ajudar na fundamentação de um argumento, com vista à tomada de decisão.

Conforme Kardec et al. (2002), muitos indicadores utilizados pelos gerentes não são adequados, consequentemente, eles não têm capacidade de especificar ou direcionar que ações a gestão da organização deve tomar para melhorar 0 desempenho do sistema produtivo.

Descrevendo sobre a implementação de um sistema de indicador de desempenho, Leão et al. (2008) alertam que é necessária uma infraestrutura tanto dos gerentes quanto daqueles que vão coletar, analisar e comunicar os dados envolvidos no processo. Portanto, conforme os autores, a instituição tende estar capacitada para manter um ambiente que ofereça suporte à implementação do sistema de avaliação. 


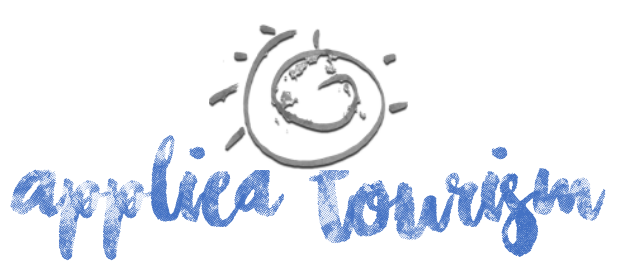

Volume 2, número 3, 2017, p. 115-135

Ao mencionar sobre 0 monitoramento de indicadores de desempenho, Leão et al. (2008) descrevem que essa ação deve ser feita após o levantamento de problemas e durante a implementação de possíveis soluções. 0 uso dos indicadores deve se tornar uma das estratégias que garantem a continuidade do trabalho.

Ao descrever sobre a relevância da utilização do indicador pelos gestores, Fernandes (2004) afirma que 0 uso do indicador leva 0 gerente a observar tanto 0 desempenho de cada processo quanto a empresa toda.

Nesse sentido, Castelli (2006) ressalta que para as empresas operarem suas atividades, elas devem possuir processos que devem estar conectados entre si, sempre visando à definição e conquista de uma meta.

Assim, como organizações que são, as lavanderias também devem fazer 0 acompanhamento de seus processos através dos indicadores de desempenho, para dessa

forma poder obter dados que possam permitir à gestão a devida análise, verificando resultados que auxiliem na tomada de decisões.

A seguir, são apresentados conceitos de lavanderia, normas e definições referentes ao processamento de lavagem de enxoval em serviços de saúde.

\section{LAVANDERIA}

Segundo o manual de normas da Anvisa (2009) que estabelece diretrizes para 0 processamento de roupas de serviços de saúde, a lavanderia hospitalar é considerada um setor de apoio, que tem como finalidade coleta, pesagem, separação, processamento, confecção, reparo e distribuição de roupas em condições de uso nas unidades do serviço de saúde.

De acordo com esse manual, a lavanderia exerce uma atividade especializada, que pode ser própria ou terceirizada, devendo sempre garantir 0 atendimento da demanda e a continuidade da assistência. 


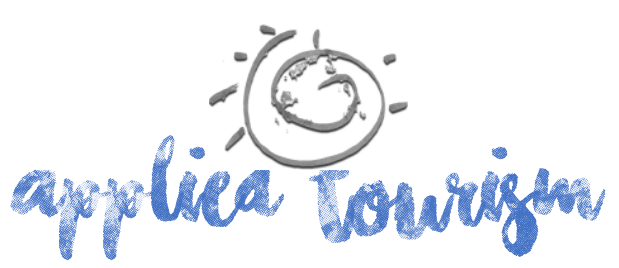

Volume 2, número 3, 2017, p. 115-135

Ao definir as etapas do processamento de roupas de acordo com a Resolução da Diretoria Colegiada (RDC) número 6, normatizada pela Anvisa (2012), estabelecem-se como etapas que compreendem esse serviço: a) retirada e acondicionamento da roupa suja da unidade geradora; b) coleta e transporte da roupa suja até a unidade de processamento; c) recebimento, pesagem, separação e classificação da roupa suja; d) processo de lavagem; e) centrifugação, secagem e calandragem; f) dobra, embalagem e armazenamento da roupa limpa; e g) transporte e distribuição da roupa limpa. Conforme a RDC 6, essas etapas têm como objetivo final garantir as condições de higiene e qualidade das roupas utilizadas na assistência à saúde.

Ao referir-se sobre lavanderia hospitalar, Cargnin (2008) explica que é o setor responsável pelo processamento e distribuição de roupas hospitalares em condições totais de higiene. De acordo com 0 autor, para que ocorra 0 processamento sem riscos ao trabalhador e em condições de higiene, os serviços de lavanderia devem seguir suas legislações.

Ao tratar sobre a importância da lavanderia hospitalar, Pereira (2012) aponta que é um dos setores de apoio mais importantes de um hospital, pois é responsável por todo processamento de roupas e distribuição em condições de higiene, conservação e segurança para toda a unidade hospitalar.

Descrevendo o objetivo básico das lavanderias, Pereira (2012) enfatiza que as lavanderias hospitalares têm como objetivo básico transformar com segurança a roupa suja e contaminada em roupa limpa. Segundo o autor, para que isso ocorra, é preciso contar com bons equipamentos e muita eficiência no processo de lavagem.

Siqueira (2005) alerta que a lavanderia hospitalar é muitas vezes um setor "ignorado dentro do hospital, sendo que, na maioria das instituições, não há um controle rigoroso dos custos e da qualidade do processamento dos enxovais" 


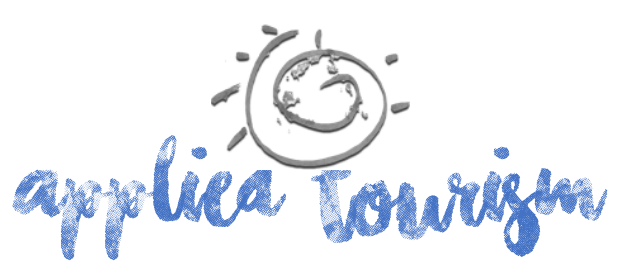

Volume 2, número 3, 2017, p. 115-135

De acordo com esse manual, a lavanderia exerce uma atividade especializada, que pode ser própria ou terceirizada, devendo sempre garantir 0 atendimento da demanda e a continuidade da assistência.

Ao definir as etapas do processamento de roupas de acordo com a Resolução da Diretoria Colegiada (RDC) número 6, normatizada pela Anvisa (2012), estabelecem-se como etapas que compreendem esse serviço: a) retirada e acondicionamento da roupa suja da unidade geradora; b) coleta e transporte da roupa suja até a unidade de processamento; c) recebimento, pesagem, separação e classificação da roupa suja; d) processo de lavagem; e) centrifugação, secagem e calandragem; f) dobra, embalagem e armazenamento da roupa limpa; e g) transporte e distribuição da roupa limpa. Conforme a RDC 6, essas etapas têm como objetivo final garantir as condições de higiene e qualidade das roupas utilizadas na assistência à saúde.

Ao referir-se sobre lavanderia hospitalar, Cargnin (2008) explica que é o setor responsável pelo processamento e distribuição de roupas hospitalares em condições totais de higiene. De acordo com 0 autor, para que ocorra 0 processamento sem riscos ao trabalhador e em condições de higiene, os serviços de lavanderia devem seguir suas legislações.

Ao tratar sobre a importância da lavanderia hospitalar, Pereira (2012) aponta que é um dos setores de apoio mais importantes de um hospital, pois é responsável por todo processamento de roupas e distribuição em condições de higiene, conservação e segurança para toda a unidade hospitalar.

Descrevendo o objetivo básico das lavanderias, Pereira (2012) enfatiza que as lavanderias hospitalares têm como objetivo básico transformar com segurança a roupa suja e contaminada em roupa limpa. Segundo o autor, para que isso ocorra, 


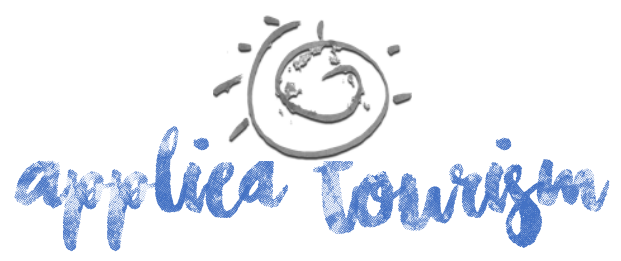

Volume 2, número 3, 2017, p. 115-135

é preciso contar com bons equipamentos e muita eficiência no processo de lavagem.

Siqueira (2005) alerta que a lavanderia hospitalar é muitas vezes um setor "ignorado dentro do hospital, sendo que, na maioria das instituições, não há um controle rigoroso dos custos e da qualidade do processamento dos enxovais" (SIQUEIRA, 2005, p. 3). Nesse sentido, o autor sugere a terceirização, que deve ser realizada por uma empresa especializada, que possua um controle de qualidade na prestação desse serviço.

Ao tratar sobre 0 conceito de terceirização dos serviços, Boeger (2008, p. 75) enfatiza que esse tipo de prestação de serviço pode ser conceituado como sendo "0 processo de permitir o gerenciamento das atividades-meio de uma empresa por empresas especialistas em busca de qualidade superior, flexibilidade e ganhos econômicos". De acordo com 0 autor, as atividades que geralmente são terceirizadas em hospitais são aquelas que estão ligadas ao setor de hotelaria hospitalar.

Neste sentido, ao descrever sobre a terceirização dos serviços de lavanderia, Siqueira (2005) enfatiza que a busca da terceirização dos serviços de lavanderia pelos hospitais tem ocorrido devido ao alto custo com a manutenção e depreciação dos equipamentos.

De acordo 0 autor, os hospitais estão com 0 foco cada vez mais voltado para 0 usuário. Nesse sentido, algumas empresas estão optando pela terceirização dos serviços de apoio, para assim tentar dar o máximo de atenção às questões envolvidas diretamente ao cliente.

\section{PROCEDIMENTOS METODOLÓGICOS}




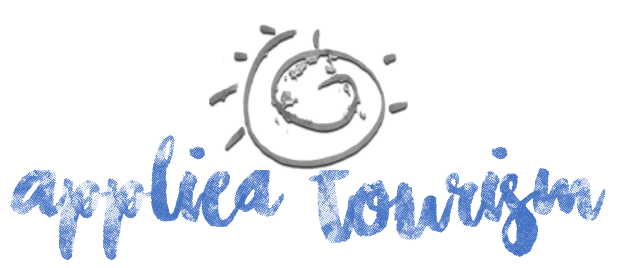

Volume 2, número 3, 2017, p. 115-135

A presente pesquisa é de natureza básica, de abordagem qualitativa, que, conforme Gil (2008), procura desenvolver os conhecimentos científicos sem a preocupação direta com suas aplicações "[...] seu desenvolvimento tende a ser bastante formalizado e objetivo" (GIL, 2008, p. 26). De acordo com 0 autor, a análise dos dados na pesquisa qualitativa passa a depender muito da capacidade e do estilo do pesquisador.

Quanto aos objetivos, trata-se de uma pesquisa exploratória, que, conforme Gil (2008), envolve levantamentos bibliográficos e documentais, além de entrevistas não padronizadas e estudos de caso. Para 0 autor, ela tem como principal finalidade "desenvolver, esclarecer e modificar conceitos e ideias, tendo em vista a formulação de problemas mais precisos ou hipóteses pesquisáveis para estudos posteriores” (GIL, 2008, p. 27).

0 presente estudo se propôs a analisar a variável indicador de desempenho relave da Lavanderia Classe A, assim como responder a seguinte questão: como a Lavanderia Classe A utiliza os resultados do indicador relave? Para atingir esse objetivo, utilizou-se, em um primeiro momento, a técnica de pesquisa bibliográfica, que, conforme Gil (2008), é desenvolvida a partir de material já elaborado, constituído principalmente de livros e artigos. Para 0 autor, esse tipo de pesquisa tem como a principal finalidade desenvolver e esclarecer ideias e conceitos para a elaboração do referencial teórico.

Em um segundo momento, a técnica utilizada foi 0 estudo de caso, que, segundo Dencker (1998), "pode envolver exame de registros, observação de ocorrências de fatos, entrevistas estruturadas e não estruturadas ou qualquer outra técnica de pesquisa” (DENCKER, 1998, p. 127).

0 critério de escolha pela Lavanderia Classe A foi por ela ser uma lavanderia industrial referência nesse segmento do município de Foz do Iguaçu, Paraná, tanto 


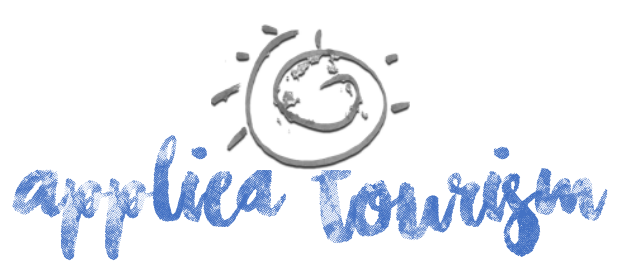

Volume 2, número 3, 2017, p. 115-135

Foi aplicado um questionário estruturado contendo 16 questões com a finalidade de conhecer: a) histórico da Lavanderia Classe A; b) procedimentos de lavagem do enxoval; e c) indicadores de desempenho que a lavanderia utiliza, especificamente, o indicador relave. Quem respondeu as questões foi a sócia proprietária da Lavanderia Classe A.

\section{ANÁLISE DOS DADOS}

A Lavanderia Classe A é uma lavanderia industrial de $1.200 \mathrm{~m}^{2}$ localizada na Avenida Jules Rimet, 867, no município de Foz do Iguaçu, Paraná. Atualmente, conta com 2 sócios proprietários, ocupando os cargos de diretor de produção e diretor comercial. Iniciou suas operações na cidade em 17/01/2013.

Sua clientela é composta tanto pelo segmento hospitalar (1 hospital e 2 clinicas), quanto pelo segmento hoteleiro (5 hotéis). Seu processamento de lavagem de enxovais atinge uma média 100 toneladas de roupas / mês. Desses, $60.000 \mathrm{~kg}$ de enxoval é hospitalar e $40.000 \mathrm{~kg}$ de enxoval é hoteleiro.

Para atender aos dois diferentes segmentos, a lavanderia conta com um total de 17 equipamentos, distribuídos em 4 lavadoras de 126 kg, 4 lavadoras de 56 kg, 1 lavadora de $26 \mathrm{~kg}$, 4 secadoras de $100 \mathrm{~kg}$, 2 secadoras de $56 \mathrm{~kg}$ e 2 calandras.

A lavanderia opera $18 \mathrm{~h}$ por dia, com os horários de funcionamento de suas atividades de 06:00h até 00:00h durante os sete dias da semana. A equipe de trabalho é composta por 66 funcionários, que são divididos nos seguintes setores: a) área crítica (hoteleira e hospitalar); b) área limpa (hoteleira e hospitalar); c) casa de máquinas; d) área de insumos; e) sala de convivência; e f) setor administrativo.

0 setor nominado como sujo crítico da área hospitalar é o local em que são descarregados os carros que chegam dos hospitais. Em média, são efetuadas 5 coletas de enxoval por dia, sendo 2 pela manhã, 2 à tarde e 1 à noite, seguindo horários determinados. 


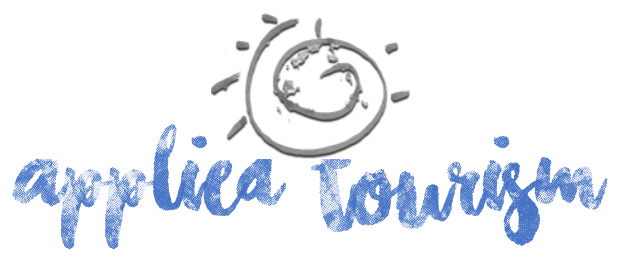

Volume 2, número 3, 2017, p. 115-135

Os funcionários que fazem a classificação das roupas são os mesmos que fazem a retirada dos hampers do carro que chega à área suja. Logo depois, com objetivo garantir a proteção e segurança dos funcionários, durante o processo de manuseio das peças, faz-se um processo de verificação da existência de material perfurocortante, com a ajuda de um detector de metal.

0 próximo passo é a classificação por tipo de enxoval e por tipo de sujidade, e em seguida é efetuada a pesagem do enxoval. A lavanderia utiliza esse processo de pesagem para que se tenha um controle da quantidade de peso colocado na máquina, sendo essa uma ação que segue as especificações do fabricante para cada equipamento. Esse peso é anotado em uma planilha junto com informações da máquina que irá realizar a lavagem, sendo tais informações necessárias para controle interno.

Após a lavagem, as roupas passam pelo processo de centrifugação nas próprias lavadoras extratoras. Em seguida, são retiradas pelos funcionários das máquinas já na área limpa, pois as lavadoras com barreira possuem duas portas, uma na área suja e outra na área limpa.

As toalhas e enxovais de campo cirúrgico são enviados para a dobra, sem passar pela calandra. Já as peças planas, como lençóis e fronhas, são encaminhadas à área da calandra.

Após passar pela secagem e dobra, as peças passam por um processo de revisão e aprovação, quando então são destinadas à calandra. 0s funcionários analisam peça por peça, e as que apresentarem manchas ou resíduos acabam sendo separadas e colocadas novamente no processo de lavagem. Estas peças que voltam para o processo inicial de lavagem são denominadas de relave.

Em seguida, as roupas limpas que passaram pela aprovação são empacotadas e novamente pesadas. 0 enxoval, então, é acondicionado em um carrinho para ser guardado posteriormente. Finalmente, as roupas são colocadas dentro do carro de transporte e entregues aos clientes. 


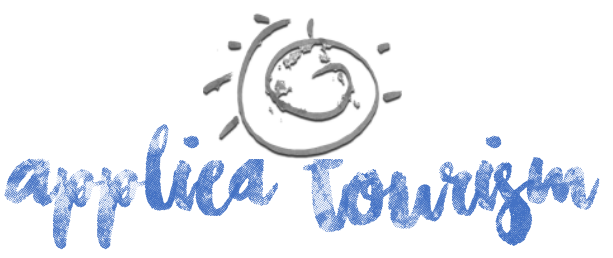

Volume 2, número 3, 2017, p. 115-135

\subsection{DADOS D0 PROCESSAMENTO DE LAVAGEM DO ENXOVAL}

A Figura 1 apresenta a quantidade anual de enxovais processados pela Lavanderia Classe A na área de hotelaria hospitalar. Os dados apresentados referem-se ao período estudado nessa pesquisa, anos de 2013, 2014 e 2015. De acordo com a figura, pode-se identificar qual ano teve a maior e a menor quantidade de enxovais processados.

Figura 1. Total de enxoval processado nos anos de 2013, 2014 e 2015.

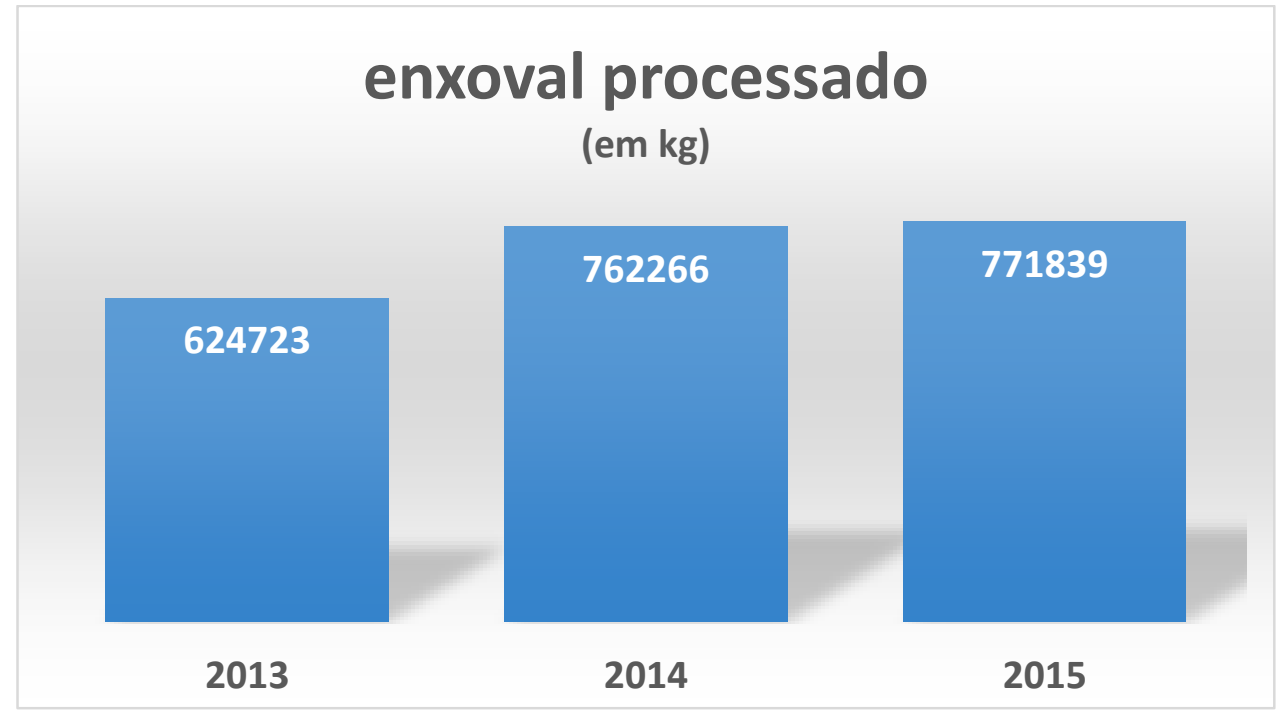

Fonte: Dados disponibilizados pela entrevistada, 2016.

0 ano que obteve a menor quantidade de enxovais processados foi 2013, atingindo $624.723 \mathrm{~kg}$. Esse montante refere-se ao período de 10 meses de operação, pois nos 


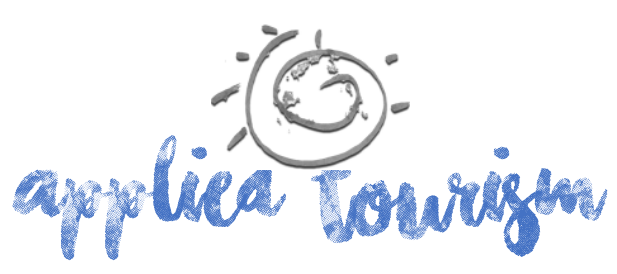

Volume 2, número 3, 2017, p. 115-135

meses de janeiro e fevereiro os dados não foram coletados: segundo a proprietária, nesse período inicial, a lavanderia estava em adaptação, já que a mesma foi inaugurada em janeiro daquele ano.

№ ano de 2014, foram processados $762.266 \mathrm{~kg}$; de acordo com a proprietária, essa quantidade era prevista pela lavanderia. 0 ano de 2015 teve elevação nos resultados do processamento de roupas, chegando a $771.839 \mathrm{~kg}$. Esse aumento se justifica devido a uma greve ocorrida nos dois primeiros meses desse ano no hospital público localizado na cidade, consequentemente, muitos atendimentos que ali eram realizados foram direcionados ao hospital que a lavanderia atende.

Analisando de forma geral, percebe-se que a quantidade de enxovais processados pela Lavanderia Classe A aumentou consecutivamente: a mesma chegou a processar nesses três anos pesquisados o equivalente a $2.158 .828 \mathrm{~kg}$ de enxoval, atingindo nesse período uma média mensal de $63.494,94 \mathrm{~kg}$ de roupas processadas. Ao explicar sobre os diferentes tipos de sujidade do enxoval, a proprietária da Lavanderia comentou que na maioria das cirurgias são utilizados produtos contendo óleos, pomadas, medicamentos de cores fortes, além do sangue decorrente do procedimento. Ao entrar em contato com o enxoval, em muitos casos, acabam manchando os mesmos, fazendo com que algumas peças tenham a necessidade de voltar ao processo de lavagem, em processo denominado relave. Para que se tenha um melhor entendimento, na sequência são apresentadas informações referentes ao indicador relave da Lavanderia Classe A nos anos pesquisados.

\subsection{DADOS D0 INDICADOR RELAVE}

De acordo com a proprietária da Lavanderia Classe A, o processo de relave ocorre após a lavagem completa da peça. Segundo ela, se no momento da dobradura for 


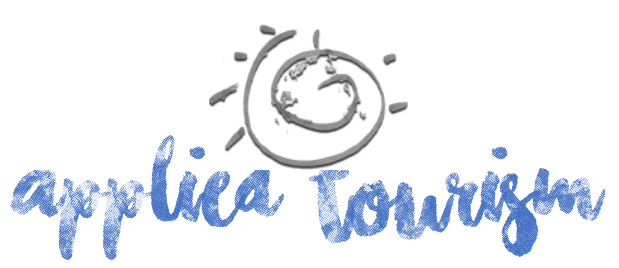

Volume 2, número 3, 2017, p. 115-135

Fonte: Dados fornecidos pela entrevistada, 2016.

Observando a Figura 2, verifica-se que 0 ano de 2013 apresenta 0 relave referente ao período de 10 meses, pelo fato da Lavanderia Classe A não possuir os dados referentes aos meses de janeiro e fevereiro. Segundo a proprietária, o início da operação da lavanderia ocorreu em março. Ela enfatiza que, ao iniciar as atividades, nem os gestores nem a equipe tinham experiência no processo de classificação de roupas, além disso, esse período foi de teste dos produtos que seriam utilizados, como também a adaptação das máquinas. Nesse sentido, ela ressalta que qualquer erro ocasionaria um aumento do indicador relave, porém observa-se que ele se manteve abaixo dos 5\%, o que é um percentual aceitável, segundo definido pela gestão da lavanderia.

No ano de 2014, o percentual de relave atingiu uma média anual de 5,01\%, percentual esse superior ao ano de 2013. Esse fato se explica devido aos meses de setembro, outubro, novembro e dezembro de 2014: nesses meses, a gestão da lavanderia percebeu que o relave teve um aumento significativo, atingindo 6,21\%, 0 que fez com o processo de lavagem fosse revisto.

Para a proprietária, esse aumento tornou-se motivo de preocupação, pois 0 relave gera custos para a empresa, em função da utilização de mais produtos, mais energia, mais água, mais desgaste das máquinas e, consequentemente, um maior desgaste do enxoval. Sendo assim, em dezembro de 2014, quando atingiu 0 ápice de 6,68\%, a gestão da lavanderia decidiu efetuar a troca do fornecedor de produtos químicos. A partir daí, foram feitos vários testes, entretanto, o problema persistiu até maio do ano seguinte.

0 montante de enxoval processado no ano de 2014 atingiu o equivalente a 762.266 $\mathrm{kg}$ de roupas, apresentando uma média de 5,01\% de relave. No ano de 2015, após mudança do fornecedor de produtos químicos, a lavanderia passou a utilizar produtos enzimáticos. De acordo com a proprietária, esse novo produto apresenta outra composição, não utiliza cloro, e deixa as roupas com um tom mais branco, 


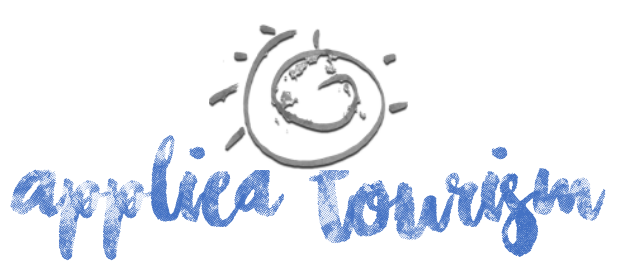

Volume 2, número 3, 2017, p. 115-135

além de proteger as peças. Essa substituição fez com que os índices de relave começassem a diminuir, apresentando uma média anual de 4,66\% do indicador de desempenho relave, mesmo com uma quantidade maior de enxovais processados. Conforme Farias (2006), os produtos enzimáticos são produtos preparados em forma de pó, líquida ou pastosa que agem como acelerador biológico, proporcionando reações químicas específicas. Segundo 0 autor, estes produtos são usados geralmente no processo de lavagem, amaciamento, desengomagem e nos processos envolvendo sujidade, como sangue.

Conforme a sócia proprietária da lavanderia, a vantagem da formulação de detergentes que contenham enzimas é a substituição de produtos cáusticos, que podem provocar lesões ao ser humano, que agridem o meio ambiente e que provocam o desgaste maior dos tecidos.

A Lavanderia Classe A trabalha com um valor aceitável máximo para 0 indicador de desempenho relave que é de 5\%. Mas, mesmo assim, a gestão foi em busca de soluções que reduzissem esse indicador. Essa decisão foi tomada devido ao acréscimo significativo do indicador no ano de 2014, que acabou resultando na utilização de produtos à base de enzima. A troca por produtos enzimáticos, de acordo com a proprietária, fez com que os resultados fossem bastante expressivos, tanto na higienização do enxoval, na maciez das fibras, na suave fragrância de limpeza, quanto na diminuição do volume de água utilizada no processamento.

Segundo ela, os clientes demonstraram estar mais satisfeitos em relação a qualidade dessa prestação de serviços, mesmo que essa substituição tenha ocasionado um aumento no valor da prestação de serviço. Nesse sentido, ela ressalta que, muitas vezes, os clientes preferem pagar um preço maior para receber um serviço de qualidade, que nesse caso oferece economias futuras, pois se o uso do produto diminui 0 relave, diminui também 0 desgaste das peças, consequentemente, há uma maior vida útil desse enxoval.

\section{CONSIDERAÇÕES FINAIS}




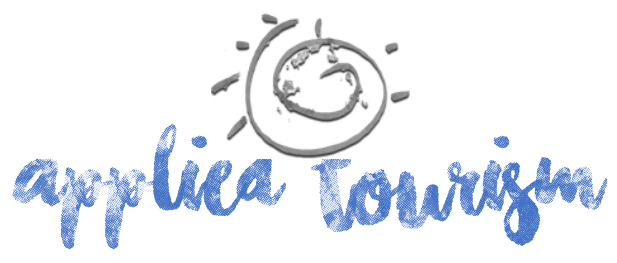

Volume 2, número 3, 2017, p. 115-135

A Lavanderia Classe A é uma lavanderia industrial que atende tanto o segmento hospitalar quanto o hoteleiro. No que se refere a esta pesquisa, foram utilizados dados referente ao processamento de lavagem do enxoval hospitalar, mais especificamente, 0 indicador de desempenho relave, que evidencia a necessidade de determinada peça passar por um novo processamento geral de lavagem.

Ao tratar da quantidade de enxoval hospitalar processado anualmente pela lavanderia, verificou-se que esse valor se apresentou de forma crescente ano após ano. Em 2013 o processamento do enxoval atingiu uma média de $624.723 \mathrm{~kg}$, no ano seguinte elevou-se para $762.266 \mathrm{~kg}$ o enxoval processado. E no ano de 2015 , os dados demonstram uma quantidade ainda maior de processamento de lavagem do enxoval, chegando a $771.839 \mathrm{~kg}$.

0 objetivo dessa pesquisa foi analisar o indicador de desempenho relave da Lavanderia Classe A. Os resultados obtidos são representados anualmente através dos gráficos dos três anos pesquisados. No ano de 2013, os resultados do indicador apresentaram um percentual de 4,48\%, valor esse que, segundo a proprietária, se manteve abaixo do valor estimado como meta da lavanderia, que é de 5\%.

Em 2014, o percentual de relave atingiu uma média anual de 5,01\%. Este percentual, superior a a ano de 2013, fez com que a gestão revisse o processo de lavagem. 0 aumento do indicador gera maiores custos para a empresa, através da utilização de mais produtos, mais energia, mais água, mais desgastes das máquinas e, consequentemente, um maior desgaste do enxoval. Sendo assim, naquele ano a gestão decidiu trocar o fornecedor de produtos químicos.

No ano de 2015, após a substituição dos produtos químicos, os valores do indicador relave apresentaram um retrocesso, encerrando 0 ano com uma média de $4,66 \%$, considerando ainda que, naquele ano, ocorreu um aumento do volume de enxoval processado pela lavanderia.

Mediante a análise apresentada, pode-se concluir que a decisão da gestão em substituir os produtos de lavagem por outros produtos à base de enzimas gerou 


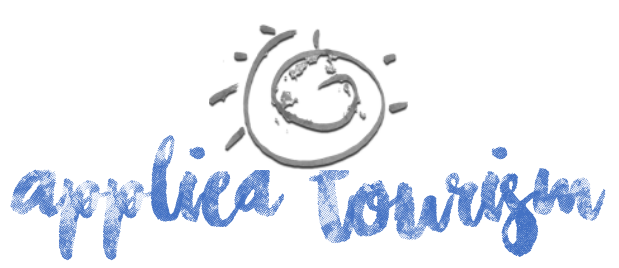

Volume 2, número 3, 2017, p. 115-135

resultados positivos, que podem ser observados tanto na higienização do enxoval através da maciez das fibras, da suave fragrância de limpeza, quanto na diminuição do volume de água utilizado durante o processamento. Além disso, os clientes demonstraram estar mais satisfeitos em relação à qualidade da prestação de serviços.

Destaca-se que os produtos enzimáticos têm um custo maior. Mesmo assim, segundo a proprietária, muitas vezes os clientes preferem pagar um preço maior para ter um serviço de qualidade superior, que oferece economia futuras, pois se 0 produto diminui a necessidade de relave, diminui também 0 desgaste das peças, 0 que resulta em maior vida útil ao enxoval.

Nesse sentido, enfatiza-se que as empresas devem estar atentas a operação de seus processos, estabelecendo indicadores de desempenho que permitam medir a eficácia das ações tomadas. No segmento de lavanderia, esse acompanhamento se faz mister em vários aspectos, seja na manutenção da qualidade e durabilidade do enxoval, seja no controle da utilização da água.

Diversas investigações podem ser feitas a partir desta pesquisa, com 0 intuito de analisar a maneira que os indicadores de desempenho podem auxiliar a gestão na identificação dos pontos fracos do processo, permitindo assim uma observação mais minuciosa, a fim de detectar possíveis problemas que estão causando os resultados indesejados. Estimula-se a reprodução do estudo, tanto em lavanderias inseridas na estrutura dos meios de hospedagem, quanto em lavanderias terceirizadas, visando comparações dos resultados e enriquecimento da pesquisa.

\section{REFERÊNCIAS}

Agência Nacional de Vigilância Sanitária. Processamento de roupas em serviços de saúde: prevenção e controle de riscos. Brasília: ANVISA, 2009. Disponível em: http://migre.me/tMEfS. Acesso em 12/05/2016. 
